Molecules 2004, 9, 627-631

molecules

ISSN 1420-3049

http://www.mdpi.org

\title{
Convenient Replacement of the Hydroxy by an Amino Group in 4-Hydroxycoumarin and 4-Hydroxy-6-methyl-2-pyrone under Microwave Irradiation
}

\author{
Edmont V. Stoyanov and Ivo C. Ivanov*
}

Faculty of Pharmacy, Medical University of Sofia, Dunav 2, BG-1000 Sofia, Bulgaria; Tel. (+359) 2 9236533, Fax (+359) 29879874.

* Author to whom correspondence should be addressed; E-mail: ivo43bg@yahoo.co.uk

Received: 4 June 2004 / Accepted: 18 June 2004 / Published: 31 July 2004

\begin{abstract}
The reaction of 4-hydroxycoumarin (1) with some primary amines $\mathbf{2 a - h}$ and morpholine (2i) under microwave irradiation occurred without opening of the lactone ring to give $N$-substituted 4-aminocoumarins 3a-i in excellent yields. Under the same experimental conditions, 4-hydroxy-6-methyl-2-pyrone (4) reacted with benzylamine (2e) or 2-phenylethylamine (2f) to give the corresponding $N, N^{\prime}$-disubstituted 4-amino-6-methyl-2-pyridones 5e,f. The main advantages of this procedure are dramatically shortened reaction times, higher amine utilization and considerably improved yields.
\end{abstract}

Keywords: 4-Hydroxycoumarin, 4-aminocoumarins, 4-hydroxy-2-pyrones, 4-amino-2-pyridones, microwave irradiation, nucleophilic replacement.

\section{Introduction}

Coumarin is an important structural moiety present in a variety of natural and synthetic products that possess significant biological activities [1]. The action of primary aromatic, arylaliphatic and aliphatic amines on 4-hydroxycoumarin (1) (Scheme 1) results in the formation of $\mathrm{N}$-substituted 4 aminocoumarins [2-4]. The latter compounds have also been prepared by the reaction of 4-halogenocoumarins with amines together with (o-hydroxyphenyl)propiolamide by-products formed by opening of the $\alpha$-pyrone ring followed by elimination of hydrogen halogenide [5]. It was also found that refluxing 1 in an excess of amine $\mathbf{2}$, in the presence or absence of a solvent, yielded a mixture of 
the corresponding ring-opened phenol and 3 [2]. However, only the target 4-aminocoumarins have been successfully obtained in many cases [4]. Some of the prepared compounds of type 3 showed antimicrobial activity [2]. It was recently reported that refluxing $\mathbf{1}$ in glacial acetic acid with an excess of primary amine prevented lactone ring opening and increased the yield [3]. Disadvantages of this procedure are the long reaction times $(10-20 \mathrm{~h})$ needed for the preparation of the $N$-(monoalkyl)substituted products of type $\mathbf{3}$. The reaction of 1 with secondary amines was reported to fail [3]. All known methods require considerable excess of the amine, e.g. amine $\mathbf{2}$ /coumarin 1 molar ratios from 10:1 to 20:1 and, hence, large amine wastes.

\section{Scheme 1}<smiles>O=c1cc(O)c2ccccc2o1</smiles>

1

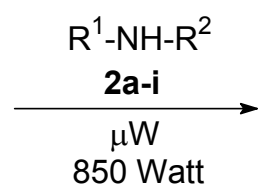

850 Watt<smiles>[R]N([R])c1cc(=O)oc2ccccc12</smiles>

3a-i

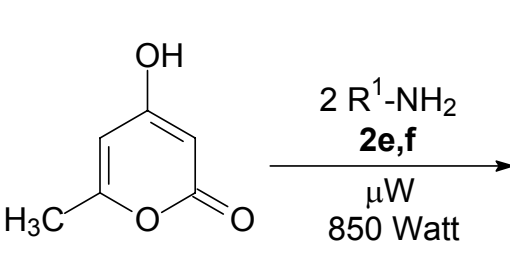

4

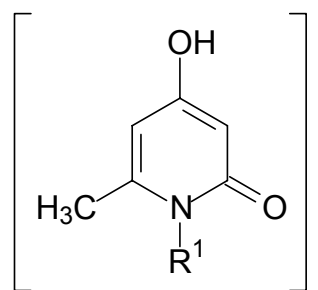

A

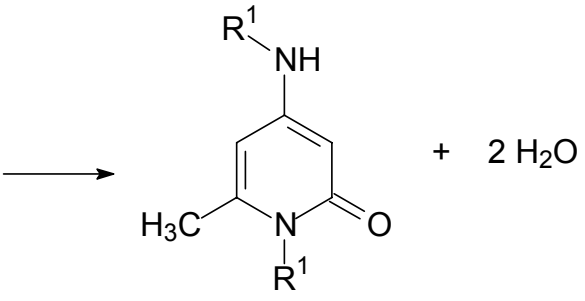

$5 e, f$

\begin{tabular}{|c|c|c|c|c|c|c|c|c|c|}
\hline $2,3,5$ & $\mathbf{a}$ & b & c & d & e & $f$ & $\mathbf{g}$ & $\mathbf{h}$ & i \\
\hline $\mathrm{R}^{1}$ & $\mathrm{n}-\mathrm{C}_{4} \mathrm{H}_{9}$ & $\mathrm{n}-\mathrm{C}_{5} \mathrm{H}_{11}$ & $c-\mathrm{C}_{6} \mathrm{H}_{11}$ & $\mathrm{C}_{6} \mathrm{H}_{5}$ & $\mathrm{C}_{6} \mathrm{H}_{5} \mathrm{CH}_{2}$ & $\mathrm{C}_{6} \mathrm{H}_{5} \mathrm{CH}_{2} \mathrm{CH}_{2}$ & $\mathrm{C}_{6} \mathrm{H}_{5}\left(\mathrm{CH}_{3}\right) \mathrm{CH}$ & $\mathrm{C}_{6} \mathrm{H}_{5}\left(\mathrm{CH}_{2}\right)_{3}$ & $\mathrm{CH}_{2} \mathrm{CH}_{2}$ \\
\hline $\mathrm{R}^{2}$ & $\mathrm{H}$ & $\mathrm{H}$ & $\mathrm{H}$ & $\mathrm{H}$ & $\mathrm{H}$ & $\mathrm{H}$ & $\mathrm{H}$ & & $\mathrm{CH}_{2} \mathrm{CH}_{2}$ \\
\hline
\end{tabular}

2-Pyridones of the type represented by $\mathbf{5}$ have been used as starting compounds for the synthesis of a series of substituted 1,2-dihydro-2-imino-7-methyl-1,6(6H)-naphthyridine-5-ones which showed antituberculosis activity [6]. In a previous paper [7] we had established that unsatisfactory yields of 5 (36-37\%) were obtained after $2-5 \mathrm{~h}$ reflux in the amine.

\section{Results and Discussion}

In this paper we describe a simple and easy microwave assisted procedure to direct replacement of the hydroxy group in 4-hydroxycoumarin (1) by some primary amines $\mathbf{2} \mathbf{a}-\mathbf{h}$ as well as the reaction of 
4-hydroxy-6-methyl-2-pyrone (3) with $\mathbf{2 e , f}$. Thus, the reaction of $\mathbf{1}$ with $\mathbf{2 a - h}$ was carried out without any solvent in a molar ratio of 1:1.2 (Scheme 1). The pressure reaction tube used for these experiments was equipped with a Teflon ring to firmly close the tube and to permit longer irradiation at $850 \mathrm{~W}$. Optimum irradiation times were precisely determined by TLC control (Merck silica gel pre-coated Alsheets) at 60, 75, 90, 105 and 120 seconds. Most yields obtained by this simple procedure were almost quantitative (Table 1), with the exception of the corresponding N-cyclohexyl derivative 3c (40\%; previously $20 \%[3])$. However, the reaction failed under the described conditions with volatile primary amines (methylamine, ethylamine, propylamine) as well as with the following primary amines: 3-amino- and 4-aminopyridine, 2-aminoethanol, and 1,2-ethanediamine. We did not succeed in isolating any pure product using secondary amines such as piperidine, $N$-methylpiperazine, 3-methylpiperazine or dibutylamine, and a complex mixture of products was obtained in each of these cases. Only when morpholine (2i) was used, the expected 4-morpholinocoumarin (3i) was prepared in very good yield (Table 1). Both new compounds $\mathbf{3 g}$,h were fully characterized by IR, ${ }^{1} \mathrm{H}-\mathrm{NMR}$ and elemental analysis.

Table 1. 4-(Alkylamino)coumarins (3a-c, e-h), 4-(Phenylamino)coumarin (3d), 4-Morpholinocoumarin (3i), and N,N'-Dialkyl-4-amino-6methyl-2-pyridones $(\mathbf{5 e}, \mathbf{f})$ prepared according to Scheme 1

\begin{tabular}{lcccc}
\hline $\begin{array}{l}\text { Starting } \\
\text { compounds }\end{array}$ & $\begin{array}{c}\text { Reaction } \\
\text { time }^{\text {a }}(\min )\end{array}$ & Product & M.p., ${ }^{\circ} \mathrm{C}$ & $\begin{array}{c}\text { Yield, } \\
\text { \% }\end{array}$ \\
\hline $\mathbf{1}+$ butylamine (2a) & 2.0 & $\mathbf{3 a}$ & $117-119[3]$ & 90 \\
$\mathbf{1}+$ pentylamine $(\mathbf{2 b})$ & 2.0 & $\mathbf{3 b}$ & $162-164[3]$ & 83 \\
$\mathbf{1}+$ cyclohexylamine $(\mathbf{2 c})$ & 2.0 & $\mathbf{3 c}$ & $193-195[3]$ & 40 \\
$\mathbf{1}+$ aniline $(\mathbf{2 d})$ & 2.0 & $\mathbf{3 d}$ & $267-268[4]$ & 97 \\
$\mathbf{1}+$ benzylamine $(\mathbf{2 e})$ & 2.0 & $\mathbf{3 e}$ & $240-242[4]$ & 98 \\
$\mathbf{1}+$ phenethylamine $(\mathbf{2 f})$ & 2.0 & $\mathbf{3 f}$ & $169-171[4]$ & 97 \\
$\mathbf{1}+$ 1-phenylethylamine $(\mathbf{2 g})$ & 2.0 & $\mathbf{3 g}$ & $186-187$ & 95 \\
$\mathbf{1}+$ 3-phenylpropylamine $(\mathbf{2 h})$ & 2.0 & $\mathbf{3 h}$ & $167-169$ & 94 \\
$\mathbf{1}+$ morpholine $(\mathbf{2 i})$ & 1.5 & $\mathbf{3 i}$ & $140-141[5]$ & 73 \\
$\mathbf{4}+$ benzylamine $(\mathbf{2 e})$ & 10 & $\mathbf{5 e}$ & $185-187[7,8]$ & 90 \\
$\mathbf{4}+$ phenethylamine $(\mathbf{2 f})$ & 10 & $\mathbf{5 f}$ & $166-168[7,8]$ & 93 \\
\hline
\end{tabular}

${ }^{\mathrm{a}}$ The reaction was carried out under $850 \mathrm{~W}$ microwave irradiation.

The same procedure was used for the reaction of 4-hydroxy-6-methyl-2-pyrone (4) with primary amines 2a-h (Scheme 1). The reaction was carried out at a pyrone 4/amine $\mathbf{2}$ molar ratio of 1:2.4 and was successful only with benzylamine (2e) and phenethylamine (2h), via opening of the lactone ring and successive recyclization to give directly the 4-amino-2-pyridones $\mathbf{5 e , f}$ in excellent yields (Table 1). A mixture of products was obtained when the power was reduced to 700 or 580 Watt. Irradiation times 
for these reactions were determined by means of TLC-control using pre-coated silica gel plates (Merck) after 1, 3, 5, 7, 9 and 10 minutes. Shorter irradiation times gave always a mixture of the starting pyrone 3 and the desired product $\mathbf{5}$. Our trials to carry out the reaction in an open vessel failed.

Compounds 5e,f were recently prepared successfully from the corresponding $N$-alkyl-4-hydroxy-6methyl-2(1H)-pyridones A under microwave irradiation ( $c f$. Scheme 1) [8]. We were not able to detect any stepwise conversion of the starting 2-pyrone $\mathbf{4}$ into $\mathbf{5}$ via $\mathbf{A}$ by means of TLC. This means that the reaction could not be stopped at the stage of an $N$-alkyl-4-hydroxy-6-methyl-2(1H)-pyridone intermediate A. In order to establish the scope of the reaction under microwave conditions, several types of amino compounds were employed. We could not isolate any pure product from the complex reaction mixtures resulting from the reaction of compound $\mathbf{4}$ with butylamine, 2-butylamine, pentylamine, cyclohexylamine, aniline, $(R)(+)$-1-phenylethylamine, 3-phenylpropylamine, 2-aminoethanol or ethylenediamine.

\section{Conclusions}

We report an efficient and simple procedure for the aminolysis of 4-hydroxycoumarin (1) and 4-hydroxy-6-methyl-2-pyrone (2) which offers significant preparative advantages over the existing methods and will make it a useful and important addition to the existing methodologies.

\section{Experimental}

\section{General procedure}

A mixture of 4-hydroxycoumarin $(1,810 \mathrm{mg}, 5.0 \mathrm{mmol})$ or 4-hydroxy-6-methyl-2-pyrone $(2,630$ $\mathrm{mg}, 5.0 \mathrm{mmol})$ and the corresponding amine $2 \mathrm{a}-\mathbf{i}(6.0 \mathrm{mmol})$ was placed in a $15 \mathrm{~mL}$ high pressure glass tube (Aldrich, length $10 \mathrm{~cm}$, with threaded type A plug and additionally provided with a Teflon ring) and placed in a $250 \mathrm{~mL}$ beaker. After microwave irradiation at $850 \mathrm{~W}$ in an ordinary domestic microwave oven (Moulinex CK3 with rotating plate) for the period of time shown in Table 1, the reaction mixture was allowed to cool to ambient temperature. Ice-cold acetone $(25 \mathrm{~mL})$ was added and the separated crystals were filtered off to give chromatographically (TLC) pure product (Table 1). The filtrate was evaporated under reduced pressure to dryness and the residue was triturated with cold diethyl ether $(10 \mathrm{~mL})$ to produce additional amounts of pure products. Compounds $\mathbf{3 g}$ and $\mathbf{3 h}$ have not been previously described.

\section{Spectral Data}

4-[(1-Phenylethyl)amino]-2H-chromen-2-one (3g): IR (nujol) cm $\mathrm{cm}^{-1}: 3345(\mathrm{NH}), 1694,1674(\mathrm{C}=\mathrm{O})$, $1549,1483,1320,1260,1188,1129 ;{ }^{1} \mathrm{H}-\mathrm{NMR}\left(250 \mathrm{MHz}, \mathrm{CDCl}_{3}\right) \delta: 1.64\left(\mathrm{~d}, J=6.8 \mathrm{~Hz}, 3 \mathrm{H}, \mathrm{CH}_{3}\right)$, $4.64_{c}\left(\mathrm{dq}, J_{d}=6.4 \mathrm{~Hz}, J_{q}=6.8 \mathrm{~Hz}, 1 \mathrm{H}, \mathrm{CH}\right), 5.18(\mathrm{~s}, 1 \mathrm{H}, 3-\mathrm{H}), 5.71$ (br. d, $\left.J_{d}=5.5 \mathrm{~Hz}, 1 \mathrm{H}, \mathrm{NH}\right), 7.15-$ 
7.4 (m, 7 $\mathrm{H}_{\text {arom. }}$ ), 7.45-7.56 (m, $1 \mathrm{H}_{\text {arom }}$ ), 7.61-7.70 (m, $1 \mathrm{H}_{\text {arom }}$ ); Analysis for $\mathrm{C}_{17} \mathrm{H}_{15} \mathrm{NO}_{2}$ (265.31): Calcd. C 76.96, H 5.70, N 5.28; Found C 76.76, H 5.66, N 5.21.

4-[(3-Phenylpropyl)amino]-2H-chromen-2-one (3h): IR (nujol) cm $\mathrm{cm}^{-1}: 3359(\mathrm{NH}), 1678(\mathrm{C}=\mathrm{O}), 1617$, $1607,1496,1557,1323,1262,1198,1123 ;{ }^{1} \mathrm{H}-\mathrm{NMR}\left(250 \mathrm{MHz}, \mathrm{CDCl}_{3}\right) \delta: 2.11_{c}$ (quintet, $J=7.1 \mathrm{~Hz}$, $2 \mathrm{H}$, middle $\left.\mathrm{CH}_{2}\right), 2.80\left(\mathrm{t}, J=7.2 \mathrm{~Hz}, 2 \mathrm{H}, \mathrm{PhCH}_{2}\right), 3.32\left(\mathrm{dt}, J_{d}=5.2 \mathrm{~Hz}, J_{t}=6.9 \mathrm{~Hz}, 2 \mathrm{H}, \mathrm{NCH}_{2}\right), 5.06$ (br., unresolved t, 1H, NH), $5.27(\mathrm{~s}, 1 \mathrm{H}, 3-\mathrm{H}), 7.1-7.4\left(\mathrm{~m}, 8 \mathrm{H}_{\text {arom. }}\right), 7.45-7.55\left(\mathrm{~m}, 1 \mathrm{H}_{\text {arom}}\right)$; Analysis for $\mathrm{C}_{18} \mathrm{H}_{17} \mathrm{NO}_{2}$ (279.34): Calcd. C 77.40, H 6.13, N 5.01; Found: C 77.18, H 6.18, N 4.94.

\section{References and Notes}

1. Hepworth, J. D. In Comprehensive Heterocyclic Chemistry; Katritzky, A. R.; Rees, C. W.; Boulton, A. J.; McKillop, A., Eds.; Pergamon Press: Oxford, 1984; Vol. 3, Chapter 2.24, pp. 799810.

2. Hishmat, O. H.; Gohar, A. M.; Wassef, M. E.; Shalash, M. R.; Ismail, I. Synthesis and biological activity of some coumarin and furocoumarin derivatives. Pharm. Acta Helv. 1977, 52, 252-255 and references cited therein.

3. Ivanov, I. C.; Karagiosov, S. K.; Manolov, I. Synthesis of 4-(monoalkylamino)coumarins, Arch. Pharm. (Weinheim) 1991, 324, 61-62 and references cited therein.

4. Tabakovic, K.; Tabacovic, I.; Ajdini, N.; Leci, O. A novel transformation of 4-arylaminocoumarins to 6H-1-benzopyrano[4,3-b]quinolin-6-ones under Vilsmeier-Haack conditions. Synthesis 1987, 308-310.

5. Zagorevskii, V. A.; Savel'ev, V. L.; Meshcheryakova, L. M. Study in pyrane series and relative compounds. 42. On synthesis of 4-aminocoumarins and on mechanism of halogen substitution in 4chlorocoumarin. Khim. Geterotsikl. Soed. 1970, 8, 1019-1023; [Chem. Abstr. 1971, 74, 76269c] and references cited therein.

6. Ivanov, I. C.; Stoyanov, E. V.; Denkova, P. S.; Dimitrov, V. S. Synthesis of substituted 1,2-dihydro-2-imino-7-methyl-1,6(6H)-naphthyridin-5-ones. Liebigs Ann./Recueil 1997, 1777-1781.

7. Ivanov, I. C.; Stoyanov, E. V.; Alexandrova, S. V. On the preparation of 4-hydroxy- and 4-amino6-methyl-2(1H)-pyridones from 4-hydroxy-6-methyl-2-pyrone. Farmatsiya (Sofia) 1997, 44, 3-6; [Chem. Abstr. 1998, 128, 243925w].

8. Heber, D.; Stoyanov E. V. The microwave assisted nucleophilic substitution of 4-hydroxy-6methyl-2(1H)-pyridones. Synlett 1999, 1747-1748.

Samples Availability: Available from the authors.

(C) 2004 by MDPI (http://www.mdpi.org). Reproduction is permitted for noncommercial purposes. 